\title{
Incorporation of Diaminopimelic Acid into the Old Poles of Escherichia coli
}

\author{
By ARTHUR L. KOCH, ${ }^{*} †$ RONALD W. H. VERWER \\ AND NANNE NANNINGA \\ Department of Electron Microscopy and Molecular Cytology, University of Amsterdam, Plantage \\ Muidergracht 14, 1018 TV Amsterdam, The Netherlands
}

(Received 11 February 1982; revised 26 May 1982)

\begin{abstract}
The surface stress theory of the ontogeny of the bacterial rod depends critically on whether the old poles continue to incorporate new material into the stress-bearing murein. If insertion of peptidoglycan continues, then seemingly the shape must become gradually rounder due to the surface stress resulting from the internal hydrostatic pressure. We have reanalysed our earlier experimental data by classifying grains with respect to distance from the nearest pole, and not from the cell centre as was done previously, and conclude that old poles do incorporate new diaminopimelic acid residues. This eliminates the model we have proposed for Gram-positive rods, which assumed diffuse growth on the cylindrical sides and that poles once formed would be rigid. The new results are consistent with another model (presented elsewhere) in which insertion of new murein occurs all over the surface, although not equally. This new model leads to elongation and division if the energetics of wall expansion is altered by the cell in a control region at a particular point of the cycle by the cell.
\end{abstract}

\section{INTRODUCTION}

Since the work of Jacob et al. (1963) the role of the cell envelope as part of a prokaryotic mitotic apparatus has been a dominant part of models for the cell cycle. The replicon model has been changed over the years by assuming that somehow the DNA must be linked to the rigid peptidoglycan portion of the wall (Schwarz et al., 1975). It has been modified for Gram-positive rods by the assumption that the origin and terminus DNA have specific binding sites at the edge of the cylindrical part and the pole, designated 'juncture sites' (Koch et al., 1981 b). Other proposals have involved the asymmetric growth of the sacculus (Donachie \& Begg, 1970; Begg \& Donachie, 1977). Although evidence against this degree of asymmetry has been presented (Staugaard et al., 1976; Verwer \& Nanninga, 1980), the original concept that the old half of a new-born cell is a unit (a 'unit cell'), has remained (Daneo-Moore \& Shockman, 1977; Sargent, 1979).

Recently a surface stress model has been proposed for shapes of bacteria and fungi (Koch et $a l ., 1981 a, 1982$; Koch 1982a, b, 1983). In the form appropriate for the Gram-positive rod (Koch et al., 1981 b, 1982), the model proposes that the poles of this organism are formed at division and afterwards are highly conserved and not turned over (Frehel et al., 1981; Fan et al., 1972, and later work summarized in Koch et al., 1981 b). The inertness of poles is essential to this submodel of the surface stress theory so that the poles can serve as the necessary rigid structure permitting diffuse cylindrical extension to take place. In this way diffuse inside-to-outside growth could theoretically take place without the structure gradually becoming more spherical. The available evidence, consistent with this, suggested that the poles turn over much more slowly than the cylindrical part (see Koch et al., 1981 b; Koch, 1983).

$\dagger$ Permanent address: Department of Biology, Indiana University, Bloomington, Indiana 47405, U.S.A.

$\ddagger$ Present address: Netherlands Institute for Brain Research, P.O. Box 41850, 1009 DB Amsterdam, The Netherlands. 
Autoradiographic studies of Escherichia coli do not provide evidence for a 'unit cell' or for a conserved pole. Lin et al. (1971) steady-state labelled single cells with diaminopimelic acid. When the organisms formed chains of unseparated cells after growth in an unlabelled but viscous medium, the chains were uniformly labelled even after four doublings. All published pulse experiments are also consistent with this observation (see Koch, 1982 b). This implies that there is no region of the wall that is conserved; rather the wall label is gradually diluted by new growth. This is not in contradiction to the results of Ryter et al. (1973), Schwarz et al. (1975) and Koppes et al. (1978), who concluded that there is intense localized incorporation in the cell centre and in lateral regions where future poles will be found. It does imply, however, that there is a second, more diffuse, growth mechanism.

A statistically more extensive analysis (Verwer \& Nanninga, 1980) confirmed these observations of the localized intense incorporation but pointed out that this is, indeed, superimposed on diffusely incorporated label. Assume, for the moment, that wall growth takes place uniformly all over the surface and that the new poles as they form are of hemispherical shape, then sites of formation of future cell poles as well as old poles would have the same intensity of labelling as the side walls after a short pulse of radioactive precursor and there would be no intense central zone. (This is because the surface of a hemisphere has the same area as does a cylinder with the same radius and length.) Four possible contributing factors to the observed intensity at central sites can be suggested. Because the pole develops initially as a narrower invagination of the murein layer (Burdett \& Murray, 1974; C. L. Woldringh, I. D. J. Burdett \& A. L. Koch, unpublished observations), one factor is that the projected area above the site of constriction represents more wall material than does the rest of the cell. The second may be that precursors are assembled there for later mobilization to other portions of the surface (De Pedro \& Schwarz, 1981; U. Schwarz, personal communication). The third possibility is that the wall in the nascent pole may be almost entirely new (prepackaged material) whereas the wall in other portions of the cell is a mixture of old and new material. The fourth is the conventional idea, which we now question, that the zones represent sites of cylindrical extension as well as sites of de novo pole formation (and, on the contrary, that grains elsewhere are due to secondary division sites, $\beta$-particles arising from the central zones, and/or turnover). In any case, the observation that wall growth is not uniform, and displays more intense zones of incorporation, has attracted interest away from the question about diffuse growth over the side wall and whether there is any insertion of new material in the completed pole of the Gram-negative rod.

\section{REANALYSIS OF DATA OF VERWER \& NANNINGA}

For the reasons given above, we have reanalysed the autoradiographs of pulse-labelled succinate-growing $E$. coli (Verwer \& Nanninga, 1980) to see how much label appears in the old poles. Previously the distance of the grains from the division furrow or geometric centre was measured; now we have remeasured the autoradiograms from the poles in order to minimize classifying the grains over poles together with grains over cylindrical parts. To do this we have counted the grains in $0.2 \mu \mathrm{m}$ intervals perpendicular to the long axis of the cells. Five regions were counted, starting at $0.4 \mu \mathrm{m}$ outside the cell and proceeding inward to $0.6 \mu \mathrm{m}$ inside the cell from each pole (see Fig. 1). By proceeding inwards only this far into the cell, the effects from the intense zones of incorporation could be virtually eliminated.

The data were normalized to $100 \%$ for the interval extending from 0.4 to $0.6 \mu \mathrm{m}$ inside the cells measured from the end of the pole. As can be seen from the original paper and those of Ryter et al. (1973), Schwarz et al. (1975) and Koppes et al. (1978), most zones of intense labelling are well outside this. However, a small proportion of the $100 \%$ may be contributed by small cells in the population that have prematurely started new zones. Another small proportion may be due to $\beta$-particles from more distant zones. While these effects should be small, they would increase the number of grains more in the $0.4-0.6 \mu \mathrm{m}$ reference interval than in regions more distal to the zones of intense incorporation. A correction for this would tend to make the experimental data fit more closely to the assumption that the poles and cylinders were equally labelled. 


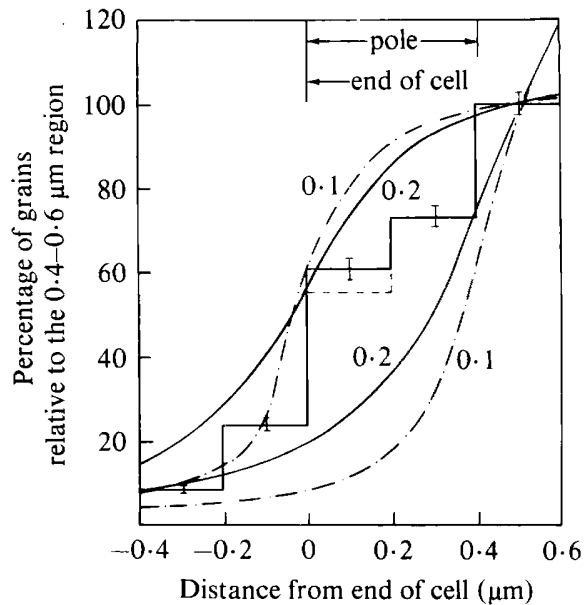

Fig. 1. Grain distribution near the poles of Escherichia coli labelled with diaminopimelic acid. The autoradiograms of Verwer \& Nanninga (1980) were remeasured taking the pole of the cell as the reference point. The abscissa indicates distance along the axis of the cells. Negative signs refer to the region outside the cell. The ordinate indicates the intensities of grains, with the grains counted in the region from $0.4 \mu \mathrm{m}$ to $0.6 \mu \mathrm{m}$ taken as $100 \%$. Four theoretical curves are shown which have been normalized to $100 \%$ at $0.5 \mu \mathrm{m}$; these were calculated as indicated in Koch $(1982 c)$, assuming a halfdistance of either $0.1 \mu \mathrm{m}$ or $0.2 \mu \mathrm{m}$ (as indicated on the smooth curves). The upper pair of curves correspond to the assumption that the pole is hemispherical and has the same degree of labelling per unit surface area as has the cylindrical portion. The lower pair of curves were calculated on the assumption that the terminal $0.41 \mu \mathrm{m}$ (the pole) is unlabelled. The experimental plot was based on counts on both poles of 545 cells of $E$. coli (W7 dap lys A) grown on $0.2 \%$ (w/v) succinate in minimal medium with a doubling time of $70 \mathrm{~min}$. The cells were starved briefly and then pulse-labelled for $9 \mathrm{~min}$ with DL-meso-2,6-diamino $\left[{ }^{3} \mathrm{H}\right]$ pimelic acid. Growth was then stopped and the cells fixed with ice-cold $1 \%(\mathrm{w} / \mathrm{v}) \mathrm{OsO}_{4}$. Washed whole cells were subjected to high-resolution autoradiography. The Poisson error of the grain counts is shown for the experimental data. Also shown, by the dashed line in the interval from 0 to $0.2 \mu \mathrm{m}$, is the correction for cells which became labelled before division and then divided during the pulse to form highly labelled, but de novo poles.

Also shown in Fig. 1 are the theoretical predictions for various distributions of label. These curves were calculated as described previously (Koch, 1982c) for an assumed half distance of the tritium $\beta$-particle in the autoradiographic technique of either $0.1 \mu \mathrm{m}$ or $0.2 \mu \mathrm{m}$. The theoretical curves in Fig. 1 were calculated on the assumption either that insertion of new material in the poles (radius $0.41 \mu \mathrm{m}$ ) is uniform or that the poles are unlabelled. It can be seen from Fig. 1 that for either choice of half distance the measured data fall in between the predictions for the two geometric cases: poles labelled and poles unlabelled. A resolution a little below a half distance of $0.1 \mu \mathrm{m}$ is possible with sectioned material if thin emulsion layers are used and the best highresolution technique employed (Salpeter \& Beckmann, 1972). De Chastellier et al. $(1975 a, b)$, for example, measured a half distance of $0.083 \mu \mathrm{m}$ for their autoradiographic procedures. Had the calculation in Fig. 1 used this half distance the theoretical curves would have had a more discontinuous character and have fitted the data less well for either choice of geometry. On the other hand, if we assume a half distance greater than $0.2 \mu \mathrm{m}$, the assumption that the poles are labelled to the same extent as the side wall would be the better fit. We believe that the half distance for our autoradiograms is between $0 \cdot 1$ and $0 \cdot 2 \mu \mathrm{m}$. This value is larger than that of De Chastellier et al. because we used whole, though flattened, cells. We estimated a half distance in this range from an examination of the concentration of label around the intensely labelled zones in constricting cells (Fig. 5 of Verwer \& Nanninga, 1980).

There is a second correction of opposite sign to the one mentioned above. This is due to the possibility that some cells become highly labelled in their nascent poles, but still complete division and separate into daughter cells within the $9 \mathrm{~min}$ pulse period. If this correction were large, it could invalidate our conclusion. It is small and can be estimated from Fig. 5 of our 
original paper (Verwer \& Nanninga, 1980). That figure shows the distribution of grains over the length of dividing cells of different size classes. The correction is made as follows: assume that the number of grains on the most intensely labelled half of the cell immediately adjacent to the central constriction represents the contribution due to the intense phase of incorporation associated with pole formation. [This is a small overestimate because grains arising from tritium atoms in the side wall region will be present as well. On the other hand, it is an underestimate because we have not taken into account other grains located elsewhere that are due to intense zones of incorporation.] The number of grains is about the same for all the size categories shown in Fig. 5 of our previous paper. The average is $2.7 \pm 0.5$ (S.D.). In this experiment the doubling time was $70 \mathrm{~min}$. From these values and the expression for the fraction of cells from any relative age, $x$, to the end of the cycle $\left(2^{1-x}-1\right)$, it can be readily calculated that $0.99 \%$ of the cells are in the interval between the first and zeroth minute before division. Assuming no lag in isotope incorporation, they will have an average of $2.7 \times 0.5 / 9$ grains. The factor $0.5 / 9$ is the ratio the mean labelling time of these cells relative to the pulse duration. Cells dividing during the $1 \mathrm{~min}$ before the end of the pulse have on the average $8.5 \mathrm{~min}$ to incorporate label. They will contribute $0.91 \%$ of the total cells of the population and have $2.7 \times 8.5 / 9$ grains. The total contribution of these one-minute classes together with the intervening 7 one-minute classes for cells that separated any time during the pulse amounts to 67 grains. When this number is normalized for the nearly 1100 poles measured to construct Fig. 1 and subtracted from the observed value, the corrected value for the $0-0.2 \mu \mathrm{m}$ interval is obtained. This is indicated by the dashed horizontal line. Similar, but much smaller corrections could have been applied to the other intervals. They would be much smaller because they are further away from the tip of the newly divided cell. The corrections calculated in this way are overestimates if there is any lag in the turnover of the precursor pools. The conclusion is clear: incorporation of new diaminopimelic acid residues takes place in the old poles at a significant, albeit somewhat smaller rate than for the side walls.

\section{DISCUSSION}

The reanalysis of the data presented here shows that established poles were labelled at roughly half the rate of the lateral walls. Thus, the pole of a Gram-negative rod like $E$. coli is not well conserved. Consequently, the surface stress growth model of a conserved pole once formed and diffuse growth of side walls does not seem appropriate for Gram-negative rods. It thus appears that the model we have proposed primarily for Gram-positive rods (Koch et al., 1981 a, b, 1982) does not apply to the Gram-negative rod. With this possible mechanism of cylindrical extension excluded, two major possibilities remain. One is that the cell has some physical template to control its width. There is partial orientation of peptidoglycan strands in the side wall of $E$. coli (Verwer et al., 1978, 1980); this probably aids in cylindrical extension by parallel attachment of new strands and this may serve to some degree as a template. Since the diameter of $E$. coli changes not only with growth conditions but also through the cell cycle (Trueba $\&$ Woldringh, 1980), a template would need to adjust according to the age and nutritional status of the cell. Consequently, ultimately the physical/chemical situation in the growing bacterium must establish the dimensions and shape. The other possibility for the Gram-negative rod is that some form of the surface stress theory functions, but with a 'variable $T$ '. By analogy with soap bubbles, $T$ is the work needed to create a new unit of surface area. The term 'variable $T$ ' has been used to classify submodels of the surface stress theory where the effective 'surface tension' varies either throughout the cell cycle and/or in different regions of the cells (Koch et al., 1982; Koch, $1982 b, 1983)$. The salient point is that it can be theoretically shown that a local decrease in $T$ would cause an invagination during further growth. The invagination arises from the same kind of forces that make a cylindrical soap bubble divide when it becomes too long.

The implications of an incorporation gradient (Nanninga et al., 1981) over the cell in terms of biochemical mechanisms of wall enlargement are also important. Imagine a diaminopimelic acid residue that by chance is incorporated near the pole of the bacterium. During subsequent growth, the residue will gradually move away from the pole and reach a more equatorial position. Many generations later it would once again find itself near the central part of the cell 
and become again part of the constriction process. Therefore, a special biochemistry cannot be postulated for peptidoglycan in poles versus side walls. This is not to say that de novo contribution to a developing pole could not be different from that to the side walls. For example, the inserted material might consist of aggregates of pre-crosslinked murein in constricting regions of the cell. This would be consistent with the suggestion of Mirelman (1979) as well as recent unpublished experiments of Olijhoek, Klencke, Nanninga \& Schwarz. In addition, it is consistent with the variable $T$ model (Koch, 1982b) because the effective surface tension of the growing wall would be lower in regions of constriction if pre-crosslinked aggregates were inserted in an extended conformation across adjacent peptidoglycan chains, while single chains alone were added to the wall in a non-constricting part of the cell wall.

This analysis highlights the difference between the Gram-positive and the Gram-negative rod. In the former there is a clear separation of the zonally formed, highly conserved poles and the rapidly turning over inside-to-outside growth of side walls in Gram-positive cells. In the Gram-negative rod, insertion of wall material takes place to some not inconsiderable degree in the old poles compared with diffuse growth over the sides; of course, the highest probability of finding incorporation is in sites of constriction or pre-constriction. But the conclusion reached here is that maintenance of the Gram-negative rod shape does not depend on diffuse side wall growth constrained by the fixed radius of two rigid poles.

A. L. Koch was supported by a Guggenheim fellowship during the period of this study. His experimental work is supported by the National Science Foundation Grant PCM 79-1141. We are grateful to J. D. H. Leutscher for help in preparing the diagram. This investigation was supported in part by the Foundation for Fundamental Biological Research (BION), which is subsidized by the Netherlands Organization for the Advancement of Pure Research (ZWO).

\section{REFERENCES}

BeGG, K. J. \& DonaChie, W. D. (1977). Growth of Escherichia coli cell surface. Journal of Bacteriology 129, 1524-1536.

BurdetT, I. D. J. \& MurRay, R. G. E. (1974). Septum formation in Escherichia coli: characterization of septal structures and the effects of antibiotics on cell division. Journal of Bacteriology 119, 303-324.

DANEo-Moore, L. \& Shockman, G. D. (1977). In The Synthesis, Assembly and Turnover of Cell Surface Components, pp. 597-715. Edited by G. Poste \& G. I. Nicolson. Amsterdam: Elsevier/North Holland.

De Chastellier, C., Hellio, R. \& Ryter, A. (1975a). Study of cell wall growth in Bacillus megaterium by high-resolution autoradiography. Journal of Bacteriology 123, 1184-1196.

De Chastellier, C., Frehel, C. \& R yter, A. (1975b). Cell wall growth of Bacillus megaterium. Cytoplasmic radioactivity after pulse-labeling with tritiated diaminopimelic acid. Journal of Bacteriology 123, 1197-1207.

De Pedro, M. A. \& Schwarz, U. (1981). Heterogeneity of newly inserted and pre-existing murein in the sacculus of E. coli. Proceedings of the National Academy of Sciences of the United States of America 78, 5856-5860.

DoNACHIE, W. D. \& BEGG, K. J. (1970). Growth of the bacterial cell. Nature, London 227, 1220-1224.

Fan, D. P., Pelvit, M. C. \& Cunningham, W. P. (1972). Structural differences between walls and ends and sides of the rod-shaped bacterium Bacillus subtilis. Journal of Bacteriology 105, 1262-1272.
Frehel, C., Beaufils, A.-M. \& Ryter, A. (1971) Etude au microscope électronique de la croissance de la paroi chez $\boldsymbol{B}$. subtilis et $\boldsymbol{B}$. megaterium. Annales de I'Institut Pasteur 121, 139-148.

JaCob, F., Brenner, S. \& Cuzin, F. (1963). On the regulation of DNA replication in bacteria. Cold Spring Harbor Symposia on Quantitative Biology 28, 329-348.

Koch, A. L. (1982a). The shape of the hyphal tips of fungi. Journal of General Microbiology 128, 947 951.

KoCH, A. L. $(1982 b)$. On the growth and form of Escherichia coli. Journal of General Microbiology 128, 2527-2539.

KосH, A. L. (1982c). Spatial resolution of autoradiograms of rod-shaped organisms. Journal of General Microbiology 128, 2541-2545.

KoCH, A. L. (1983). The surface stress theory of microbial morphogenesis. Advances in Microbial Physiology (in the Press).

Koch, A. L., Higgins, M. L. \& Doyle, R. J. ( $1981 a$ ). Surface tension-like forces determine bacterial shapes: Streptococcus faecium. Journal of General Microbiology 123, 151-161.

Koch, A. L., Mobley, H. L. T., Doyle, R. J. \& STREIPS, U. N. (1981 b). The coupling of wall growth and chromosome replication in Gram-positive rods. FEMS Microbiology Letters 12, 201-208.

Koch, A. L., Higgins, M. L. \& Doyle, R. J. (1982). The role of surface stress in the morphology of microbes. Journal of General Microbiology 128, 927 945. 
Koppes, L. J. H., Overbeeke, N. \& NanNinga, N. (1978). DNA replication pattern and cell wall growth in Escherichia coli PAT 84. Journal of Bacteriology 133, 1053-1061.

Lin, E. C. C., Hirota, Y. \& Jacob, F. (1971). On the process of cellular division in Escherichia coli. Journal of Bacteriology 108, 375-385.

Mirelman, D. (1979). Biosynthesis and assembly of cell wall peptidoglycan. In Bacterial Outer Membranes, pp. 115-166. Edited by M. Inouye. New York: John Wiley.

Nanninga, N., Woldringh, C. L. \& Koppes, L. J. H. (1981). Growth and division of Escherichia coli. In Cell Growth, pp. 225-270. Edited by C. Nicolini. New York: Plenum Publishing Co.

Ryter, A., Hirota, Y. \& Schwarz, U. (1973). Process of cellular division in Escherichia coli: growth pattern of E. coli murein. Journal of Molecular Biology 78, 185-195.

Salpeter, M. M. \& Bachmann, L. (1972). Autoradiography. In Principles and Techniques of Electron Microscopy, vol. 2, pp. 221-278. Edited by M. H. Hayat. New York: Van Nostrand Reinhold Co.

SaRGENT, M. (1979). Surface extension and the cell cycle in prokaryotes. Advances in Microbial Physiology 18, 105-176.
Schwarz, U., Ryter, A., Ramboek, A., Hello, R. \& Hirota, Y. (1975). Process of cellular division in Escherichia coli: differentiation of growth zones in the sacculus. Journal of Molecular Biology 98, 749759.

Staugaard, P., Van Den Berg, F. M., Woldringh, C. L. \& NANNINGA, N. (1976). Localization of ampicillin-sensitive sites in Escherichia coli by electron microscopy. Journal of Bacteriology 127, 1376-1381.

Trueba, F. J. \& Woldringh, C. L. (1980). Changes in cell diameter during the division cycle of Escherichia coli. Journal of Bacteriology 142, 869-878.

VERWER, R. W. H. \& NANNINGA, N. (1980). Pattern of meso-DL-2,6-diaminopimelic acid incorporation during the division cycle of Escherichia coli. Journal of Bacteriology 144, 327-336.

Verwer, R. W. H., Nanninga, N., Keck, W. \& SCHWARZ, U. (1978). Arrangement of glycan chains in the sacculus of Escherichia coli. Journal of Bacteriology 136, 723-729.

Verwer, R. W. H., Beachey, E. H., Keck, W., Stoub, A. M. \& Poldermans, J. E. (1980). Oriented fragmentation of Escherichia coli sacculi by sonication. Journal of Bacteriology 14, 327-332. 